Original Research Paper

\title{
Understanding the Prejudice and Social Exclusion of Transgender Community in Cultural and Theoretical Context
}

\author{
Syed Bahadur Abbas \\ School of International and Public Affairs, SJTU, China
}

Article history

Received: 10-09-2020

Revised: 24-10-2020

Accepted: 12-11-2020

Email: bahadur_abbas@sjtu.edu.cn

\begin{abstract}
While most of the studied focused on primary data to portray the deteriorated socioeconomic status of transgender community in Pakistan. This study takes a leverage to employ theoretical approach towards understanding the situation of Transgender community in Pakistan. This study sheds light on the problem of prejudice and social exclusion of transgender community in Pakistan's society. Despite that government's efforts to formalize legislations for the recognition of Transgender people and application of welfare policies for the betterment of transgender community, the social acceptance of transgender community is still a goal far from being achieved. The gender hierarchy of Pakistan still sees transgender people at the bottom. This study suggests the need for awareness for the gender equality and equal rights for transgender community in Pakistan.
\end{abstract}

Keywords: Transgender, Prejudice, Social Exclusion, Masculinity

\section{Introduction}

Oliven (1965), used the word Transgender to differentiate between Transsexualism and Transgenderism. The two terms are different from each other being a physical and a psychological condition, respectively. The argument was based on the discussion that the term 'Sex' refers to the biological orientation of a person's anatomy whereas the term 'Gender' refers to a person's choice of identification. Being a Transgender can be referred to a person whose sexual orientation is not same as the identity of gender.

The conflict of gender identification has long been seen as a mental disorder. It had been listed under the section F64 of WHO book for Diagnostic Criteria for Research, International Classification of Disease (ICD10), since 1992. Despite the fact that the term 'Transgender' itself is not specifically mentioned in the book but the definitions of a psychological disorder about sexual identity is quite similar to the term Transgender. There has been a profound debate that rejects Transgendersim to be a psychological disorder. This has resulted in changing how we define being a Transgender. As WHO published the 2018 edition, the condition is no longer a mental disorder (Branswell, 2016).

The diversity of the terminology encapsulated anyone who proclaims to deviate from the sex they were assigned at the time of their birth. When it comes to South Asia and especially Indian Sub-Continent the term is more often referred to the people who are either born transsexuals or tend to have traits of the opposite sex. In the cultural context, especially in the sub-continent region, being a transgender for an individual has always been frowned upon. It puts a person under an unavoidable prejudice and social exclusion from society (Agrawal, 1997).

\section{Prejudice and Social Exclusion}

Emilia et al. (2008) conducted a detailed study on transgender community and the difficulties they face. In their study they stated that most of the transgender people at workplace faced physical violence as well as psychological harassment by their coworkers. The study found that the transgender community is facing a major socio-economic set back due to the discrimination and harassment they face. In most of the cases they were being harassed by the people they are familiar with. Another finding of the study emphasized on the fact that the proportion of being harassed was relatively higher among the younger transgender people that lead to a higher probability of a specific age group of transgender community to commit suicide. The data was collected from 402 respondents through structured questionnaire throughout United States. Different variables were used in this study such as employment, ethnicity, age and income level and gender identity. More than half of the transgender people were victims of harassment, violence and social exclusion. The results of this study concluded that legislation has to be defined in order to protect the 
transgender rights and laws are needed to be developed to evict social exclusion of transgender community. The study asked for government's intervention in order to devise and employ transgender rights.

Show (2015) studied about the human rights of transgender community in India. The court of India declared that the people who cannot useful in the reproductive system are not considered as man or women. India is the first country that declared this community as third gender. The court of India said that the third gender community deserves rights in the society. In India the dead transgender has buried in his own house. The main finding of this study was that to examine the social and economic condition of transgender community and identify their problems. The data was collected from 126 people between the ages of 20 to 45 in Burdhwan district of West Bangal. The study found that mostly the lower income class joins the socially excluded community of transgender. They lack education and basic rights to begin with.

Ozturk and Tatli (2016) examined the experience of transgender community at their workplaces in UK. The transgender people faced discrimination at their workplace due to their lack of better management. The study also gives policy suggestions for organization to improve the diversity and management resources. The data was collected from 14 employees through in-depth interviews within two and half years. The study used purposive sampling and snow ball sampling technique for data collection. The study reveals that the transgender people faced discrimination at the time of selection and if they are selected after interviews then they faced biasness at the workplace. The study suggests that the organizations need proper legislation to improve the equality around the gender identity. The limitation of the study was that the data was qualitative. Further studies should take quantitative data at large scale.

\section{Being a Transgender in Pakistan}

Transgender in Sub-Continent have a certain historical significance. The history of transgender people in Indian sub-continent dates back up to four thousand years. if we take a look at the Islamic history of sub-continent, transgender people played a major role in various profession such as performing household chores and taking care of royal ladies (Giri, 2019). The professions adopted by transgender people in South Asian history also included top posts such as being advisor to the ruler and other key administrative posts. The reason behind being at the key posts and advisor for rulers may be the fact that rulers found them more trustworthy (Feener, 2007).

In the recent years in Pakistan there have been some major developments in the form of legislations to promote transgender equality through some positive steps. Up till 2012 the transgender people in Pakistan did not have a right to choose their desired gender on their National Identity Card. However under the orders passed by the Supreme Court of Pakistan petition under the article 184(3) of the constitution, National Database and Registration Authority (NADRA) was advised to add a separate section of answer under the question of gender and issue ID Cards to transgender specifying third gender on it (Express Tribune, 2012). Another positive step towards recognition of transgender community in Pakistan is there inclusion as a separate gender in the national census of 2017. On religious grounds, a Fatwa (Religious Decree) issued by at least 50 clerics allows transgender marriage for those who have visible biological signs of transsexuals (Dawn News, 2016).

In Indian Sub-Continent there are different names given to this community such as Hijra, Zanana, Khusra and Khwaja Sara (Nazir and Yasir, 2016). These names are also used as words of disgrace and abuse among general public, most often to attack masculinity. There is a lesser space for Transgender people to get out of the social exclusion in Pakistan due to the conservative social circles and gender hierarchy of Pakistan's society (Ahmed et al., 2014). Jami (2005) studied about the condition and status of the Hijras (Transgender) in Pakistan. The term Hijra in Pakistan is solely dedicated to the transgender with physical appearance of males who behave and act like Females i.e., Male-to-Female Transgender. Hijras are the most common type of transgender in Pakistan. They are further categorized as intersex, cross dresser, homosexual etc. As a factor of identification for a Hijra in Pakistani society is observing a Man's interest in makeup, dancing and behaving like a women. In most of the cases it is found that people with transgender personalities are abandoned by their families that lead them to join the Hijra community and live apart from their biological families as they are not accepted due to their sexual orientation. The main objective of this study is to highlight the poor condition of Hijras in society and their living standard. The study also looks at the issue through a religious point of view and how Pakistan has failed to provide this community even with the basic equal rights as the other fractions of society.

Despite the fact that there have been several bills and legislations passed through official parliament, it has failed to provide the Transgender community with social inclusion and equal rights. A landmark Transgender Person (Protection of Rights) Act in 2018, allowed transgender people to have identify themselves as Transgender in their National Identity Card. A large number of transgender people however did not change their gender to transgender and chose to be identified as Males, while having tendencies of opposite sex. This puts them under a stigma of being homosexual which is unacceptable in Pakistani society.

Being an Islamic Republic, Pakistan has strict rules against homosexuality, the nation absolutely rejects the 
homosexuality constitutionally. Wike et al. (2013) reported that Pakistan as being extremely intolerant when it comes to homosexuality, the report portrays a survey data taken from 39 countries through 37,653 respondents during the times of March to May of 2013, out of which 1,201 respondents were from Pakistan. $82 \%$ of the respondents from Pakistan rejected social acceptance of homosexuality. Landinfo (2013) studied about the homosexuals and homosexuality in Pakistan. As in Pakistan there is no concept of homosexuality being legal or socially acceptable. According to state laws and also Islamic perspective such act is considered completely illegal and punishable.

Despite being accepted as a group of different identity, the transgender community in Pakistan is still faces prejudice and social exclusion from the masses. The community lacks basic rights such as health facilities and education. This results in a very limited window of opportunities left for transgender community due to low education of education as well as harassment and discrimination that they have to face on daily basis.

Some of the government and non-government institutions such as military have code of conduct that does not allow transgender people to apply and join the profession as a career. This social prejudice regarding employment opportunities has been the main reason behind transgender people getting involved in illicit activities such as sex work and other socially unacceptable occupations to generate income.

Pakistan is one of the largest Islamic Republic in the world with $98 \%$ population consisting Muslims. This means that any legislation that has to be made should be in line with Islamic laws of Shariyah. Abbas et al. (2014) examined the survival of transgender community in Pakistan. Due to a nonexistent employment opportunity in Pakistan. Transgender people are left with no other choice accept being indulged in professions that are socially unacceptable, such as party entertainer, dancing, illegal prostitution and begging. Society is not ready to accept the idea of an additional gender that is equal to the existing two genders.

Acquiring education as a transgender in Pakistan is a hard task due to harassment that transgender people have to face at their educational institutions. The suggestions of many studies that have been quoted in this study stress on government to provide education to this community. There should also be religious education for this community to get them streamlined with the Islamic society of Pakistan. Tabassum and Jamil (2014) studied about the issues related to education of transgender community in Pakistan. The main objective of this study was to highlight the importance of education for this community and also checked the willingness of transgender community towards education. The study examines the opinion of transgender people about their lives. The study found the despite of having opportunity and resources to continue, some of the transgender individuals quit education and school due to the harassment and discrimination they face in their schools. The suggestions of this study were that every institution should provide equal rights to every person and should not take decisions on the basis of sex. There is need of complete laws for the welfare of transgender community within all dimensions of society. The educational needs of the third gender community should be fulfill so they can be competent to compete in every walk of life like other member of society.

Transgender community in Pakistan faces immense obstacles in order to obtain a higher socioeconomic status. Despite of recent legislation by the government and other institutions this community is still facing a lot of problems in order to attain social acceptance and facilities that are readily available for general public in Pakistan.

\section{Data and Interviews}

This study aims to provide with an insight through a descriptive analysis focused on deteriorated condition of transgender community focused in the Faisalabad District of Punjab province, Pakistan. Faisalabad is the third largest city of Pakistan and second largest city of Punjab according to the census of 2017. In-depth and semi structured face to face interviews were conducted individually with 87 transgender people to gather information about transgender community in Faisalabad. The transgender people are mostly in close contact with each other and have closely knit communities, even so that some transgender people prefer to live with their transgender friends rather than their families. Snow Ball sampling technique was used to find willing respondents for interviews. However despite of contacting some individuals with references and assurance that none of the information shall be made public, a considerable number of respondents were reluctant to share any information about their personal life. There are two main reasons that can be inferred behind the reluctance of not sharing any information. One of them is that they do not believe the interviewers any more since they have had been betrayed once or twice as some of the respondents told us that the contact information provided by them for interviews was leaked and caused a great deal of interruption in their daily life and secondly they are involved in such activities that they did not find easily socially acceptable and did not want to talk about it.

All of the respondents for the purpose of this study were Male-to-Female transgender as they are the most abundant type of transgender in the whole country. It is to be noted that only a few of the respondents had a biological anatomy of a transgender while most of the respondents were those who were physically male and acted as females or those who had gotten hormonal or other medical treatment to become more feminine. 
Age of the respondents ranged from 18 to 70 years. All of the respondents were involved in activities such as dancing at weddings and parties or begging that is why they did not have a steady source of income. As an exception, some of the respondents were making a good amount as income that put the higher income class however a vast majority of the respondents was not making enough income annually to be above the poverty line.

The level of formal education among transgender community is astonishingly low. Out of 87 respondents there was only one respondent held a college degree (14 year of education) however that individual also failed to acquire a proper job and now works as a party entertainer and dancer. $46 \%$ of the respondents never went to school or took any kind of formal education at all. Upon being asked about why they did not take any education, one respondent answered that knowing that being a transgender, there is not much of an employment opportunity hence making an income from a young age through begging seemed more appropriate than "wasting" time on education.

Despite having a choice of identifying themselves as transgender on their ID, most of the transgender people in Pakistan are still reluctant identify themselves as transgender. Only 18 out of 87 respondents had ID cards marked as transgender. The reason they provide about not having a transgender written on their ID card is that they think it makes things harder for them to carry out simple affairs such as traveling and managing other daily life activities. Most of the respondents still identify themselves as male on their documents because having a male ID card helps them to stay away from unnecessary hassle.

Most of the respondents realized about their transgender characteristics between the ages of 7 to 12 and admitted as well as publically proclaimed about it between the ages of 12 to 14 years. $90 \%$ of the respondents are still in contact with their families and $55 \%$ of the respondents are still living with their families. However some of them were instantly abandoned by their families as soon as they chose to stick with their transgender identity. Most of them came from large family having on average 5 siblings.

$64 \%$ respondents said that they have either been or still in a relationship with someone however only $25 \%$ of the respondents had partners who were open about their relationship. All 87 respondents stated that they fell much more comfortable and secure being around other transgender people. $29 \%$ of the respondents said that their families are embarrassed of them being transgender.

A large number of respondents are in contact with their immediate but only $27 \%$ respondents are invited at the family gatherings and meet their distant relative while only $28 \%$ stated that they have a say in all major decision taken by their family. Due to the ignorant behavior from their families and friends most of transgender people face a lot of psychological problems that lead to cause many problems in their lives such as generating the tendencies to commit suicide. Being asked about their mental health and wellbeing $97 \%$ respondents said they feel nervousness among unknown people and new meetings, 98\% feel constant restlessness, $89 \%$ said that they feel completely hopeless about the prosperous future of their community while $85 \%$ of the respondents stated to that they feel that their existence is unwanted and worthless. Only $26 \%$ of the respondents said that they talk about these feelings to their friends or family and none of the respondents has ever sought consultation for their psychological wellbeing.

All of the respondents in our survey were practicing Muslims out which $93 \%$ state that they regularly go to mosque and other religious gatherings. However $50 \%$ of the respondents told us that at least once in their life they have been openly told by someone that they are not allowed to enter the mosque.

Most common profession among this community is dancing at parties or weddings to make money as well as begging. However upon inquiring whether they are satisfied with their work $83 \%$ of the respondents openly said that they are not satisfied with their work at all while $94 \%$ of the respondents stated that if given a chances they would change their profession.

This study tries to quantify the prejudice and social exclusion faced by the transgender community by society. There were 14 different questions of dichotomous nature used to make an assessment about the prejudice towards transgender community from the society in daily life. The Table 1 shoes the questions and their responses.

These 14 questions try to assess the severity of daily life problems that this community has to face encapsulating their social, religious and family life and to quantify the discrimination that they have to face all the answers were made in an average.

Another interesting aspect that was captured in the semi structured interviews is to quantify the reverse discrimination. Through this aspect it has been observed that the discrimination is not only imposed upon this community through society and their family, but the major part of it is their own psychological condition that does allow them to move freely among masses. For an instance a question in the questionnaire was asked that if the individuals avoid doing anything of their interest only because of the fact that people might create a problem for them in that activity, it turned out that $75 \%$ of the respondents responded in Yes which implies that a large number of transgender individuals have a setback due to the prejudice the face and it does not allow them to join in the normal activities because of the fear that they might have to face problems. 
Table 1: Bivariate questions used to evaluate the prejudice against transgene community

\begin{tabular}{|c|c|c|c|}
\hline Sr\# & Questions & Yes $(\%)$ & No $(\%)$ \\
\hline 1 & Does your family feel embarrassed of you? & 28 & 72 \\
\hline 2 & Are you invited at the family gatherings? & 28 & 72 \\
\hline 3 & Does your family ask for your opinion in important matters? & 30 & 70 \\
\hline 4 & While in public, do you ever feel you are treated with lesser respect? & 92 & 8 \\
\hline 5 & Do you feel you receive poor services at stores/restaurants or other places than other customers? & 84 & 16 \\
\hline 6 & $\begin{array}{l}\text { Do you feel unconformable being called Hijra/Khusra/Khuawaja Sara/Shemale/Ladyboy or } \\
\text { other names given to you? }\end{array}$ & 74 & 26 \\
\hline 7 & Are you ever been touched inappropriately without consent? & 87 & 13 \\
\hline 8 & Do people follow you around or keep an eye on you for no reason? & 87 & 13 \\
\hline 9 & Do people mention to you the degrading myths and stereotypes attached with your community? & 95 & 5 \\
\hline 10 & Do you ever get made fun of? & 84 & 16 \\
\hline 11 & Do people think of you as less intelligent or weak than them? & 92 & 8 \\
\hline 12 & Do you always have to think in advance about the problem you might face while going out of your house? & 88 & 12 \\
\hline 13 & Do you get any better services or treatment when you are dressed well? & 64 & 36 \\
\hline 14 & Have you ever been told that you are not allowed to follow the religion you are following, by anyone? & 51 & 49 \\
\hline
\end{tabular}

Upon being inquired about the willingness of transgender to be integrated into the society, we found an interesting aspect, as the they were asked if they need to have a separate hospital only dedicated to transgender community, $79 \%$ of the respondents replied with a Yes. Similarly in another question when it was asked that should there be a separate mosque for the transgender community to freely carryout there religious activates, $83 \%$ of the respondents said that they would prefer to have a mosque of such kind.

\section{Discussion}

Most of the studies that have contributed towards studying the condition of transgender community in Pakistan have focused on the community's socio economic status, lack of basic rights and social prejudice against the community. A major aspect of analyzing the situation of transgender community is in observing gender hierarchy of Pakistani society.

The social inclusion of transgender community in Pakistan is heavily linked with the gender dynamics of Pakistan. SDPI (2005) reported that Pakistan gender hierarchy puts men on the top of the list while women are considered weaker. All the transgender people in Pakistan who have changed their identity initially identified themselves as male and all those who are still reluctant to change their identity also prefer to take male identity as their official status. The reason is the fact that most of the transgender people are reluctant to change their identity on the national identity card as well as being recorded as a transgender on official sources to keep a better opportunity for themselves to move in society.

The 2017 census of Pakistan revealed that a significant number of households despite of having a transgender member in the family, listed them as male. (Express Tribune, 2017) The final report of the census also mentions that enumerators either did not ask the question of the presence of a transgender in the family or the household head did not reveal the presence of a transgender family member. As a result only 10,418 transgender individuals were able to be recorded in the whole population of Pakistan. Which is certainly not a right number. Private organizations estimate this number up to 400,000 to 500,000 . The main reason behind reluctance towards being identified as a transgender in Pakistan links the lack of social acceptance and the stigma related with being a transgender.

Another factor to be noted from the census data was the number of transgender people was different when compared to different provinces. Apart from that the number of transgender are also very lopsided in rural and urban parts. Punjab turned out to be having the most population of transgender people which made up to $65 \%$ of the transgender population of Pakistan. It should be noted that Punjab province has a higher per capita income as compared to all other provinces (PBS, 2017).

\section{Conclusion}

In sum, this study points towards the foible that has been the reason behind government's transgender welfare policy. The policies that government has made so far, are related towards economic uplift of the society while equal focus is required towards social inclusions and social acceptance of transgender community in Pakistan. Although in the recent times government has started taking actions in order to improve the socio economic status of the transgender community however there seems to be a lack of efforts in making policies that provide social acceptance and social inclusion of transgender community. The government's efforts are subjected towards uplifting of the community however normalization of transgender person in the society does not seem to be the government's priority at the moment.

\section{Acknowledgment}

I am extremely grateful to all the participants who helped me fill in the questionnaires and making time for interviews. The participants in the study did not only provided with their own interviews but also helped me to 
find further participants from all walks of life. I am also grateful to my colleague Syed Aal e Raza Shah who advised me in formation of questionnaire and interview process throughout the study.

\section{Ethics}

Apart from the questions taken from the designed questionnaires informal conversations were carried out with the participants to get a better understanding of their personal lives. The aim of such conversations was to strengthen the bond and gain trust of participants. Since the main focus of this study has been the interviews that were carried out with participants from transgender community. Throughout the study it has been made sure that none of the personal information of any participants is made public.

\section{References}

Abbas, T., Nawaz, Y., Ali, M., Hussain, N., \& Nawaz, R. (2014). Social adjustment of transgender: A study of District Chiniot, Punjab (Pakistan). Academic Journal of Interdisciplinary Studies, 3(1), 61-61. https://doi.org/10.5901/ajis.2014.v3n1p61

Agrawal, A. (1997). Gendered bodies: the case of thethird gender'in india. Contributions to Indian Sociology, 31(2), 273-297. https://doi.org/10.1177/006996697031002005

Ahmed, U., Yasin, G., \& Umair, A. (2014). Factors affecting the social exclusion of eunuchs (hijras) in Pakistan. Mediterranean Journal of Social Sciences, 5(23), 2277-2277. https://doi.org/10.5901/mjss.2014.v5n23p2277

Branswell, H. (2016). Is being transgender a mental illness? WHO classification system suggests it is. STAT. https://www.statnews.com/2016/06/03/whotransgender-mental-illness-classification/

Dawn News. (2016) Fatwa Allows Transgender Marriage. Dawn News. https://www.dawn.com/news/1267491

Emilia, L., Ahmed, O., Badgett, M. V. L., Baker, K., ...., \& Beemyn, G., (2008). US Transgender Survey, National Centre for Transgender Equality. https://www.transequality.org/sites/default/files/docs /USTS-Full-Report-FINAL.PDF

Express Tribune. (2012). Transgender rights: NADRA provides 3 gender options on CNIC registration form. https://tribune.com.pk/story/331535/transgenderrights-nadra-provides-three-gender-categories-oncnic-registration-form

Express Tribune. (2017). Transgender Community Rejects Census Figures. https://ribune.com.pk/story/1492120/transgendercommunity-rejects-census-figures

Giri, D. (2019). Transgender in Indian Context Rights and Activism.
Feener, R. M. (2007). A MIRUL HADI, Islam and State in Sumatra: A Study of Seventeenth-Century Aceh, Islamic History and Civilization: Studies and Texts 48 (Leiden/Boston: EJ Brill, 2004). Pp. 287. \$140.00 cloth. International Journal of Middle East Studies, 39(3), 485-486. https://doi.org/10.1017/S0020743807070717

Jami, H. (2005). "Condition and Status of Hijras (Transgender, Transvestites etc.) in Pakistan (Country Report)". paper presented at the 1st International Conference: Gender and Sexualities, Bangkok, Thailand.

Landinfo. (2013). Pakistan: Homosexuals and Homosexuality. https://landinfo.no/wpcontent/uploads/2018/03/Pakistan-Homosexualsand-homosexuality-03052013.pdf

Nazir, N., \& Yasir, A. (2016). Education, Employability and Shift of Occupation of Transgender in Pakistan: A Case Study of Khyber Pakhtunkhwa. Dialogue (Pakistan), https://www.qurtuba.edu.pk/thedialogue/TD/The $\% 2$ 0Dialogue/11_2/Dialogue_April_June2016_158176.pdf

PBS. (2017). Pakistan Bureau of Statistics. http://www.pbs.gov.pk/content/population-census

Oliven, J. F. (1965). Sexual hygiene and pathology: A manual for the physician and the professions. Philadelphia: Lippincott.

Ozturk, M. B., \& Tatli, A. (2016). Gender identity inclusion in the workplace: broadening diversity management research and practice through the case of transgender employees in the UK. The International Journal of Human Resource Management, 27(8), 781-802. https://doi.org/10.1080/09585192.2015.1042902

SDPI. (2005). Panel: Displacement, Livelihoods and Rights: Gendered Experiences. http://www.sdpi.org/sdc/8thsdc/Womens-GenderIssues/womens_gender_issues_1.htm

Show, K. K. (2015). Human rights perspectives of the third gender in India. The Rights, 1(10), 1-7. https://yior.org/wpcontent/uploads/2019/01/Kamal_Kant_Show.pdf

Tabassum, S., \& Jamil, S. (2014). Plight of marginalized: Educational issues of transgender community in Pakistan. Review of Arts and Humanities, 3(1), 107-122. https://www.researchgate.net/publication/26478574 4_Plight_of_Marginalized_Educational_Issues_of_ Transgender_Community_in_Pakistan

Wike, R., Horowitz, J., Simmons, K., Poushter, J., Ponce, A., Barker, C., \& Devlin, K. (2013). The Global Divide on Homosexuality. Pew Global Attitudes Project. Washington, DC: Pew Research Center. https://assets.pewresearch.org/wpcontent/uploads/sites/2/2014/05/Pew-Global-AttitudesHomosexuality-Report-REVISED-MAY-27-2014.pdf 